\title{
Design Practices used in the development of Microfluidic Devices: A services based view
}

\author{
Katarzyna Panikowska, Ashutosh Tiwari, Jeffrey Alcock, Christopher Turner* \\ Email: katarzyna.panikowska@gmail.com \\ Email: a.tiwari@cranfield.ac.uk \\ Email: j.r.alcock@cranfield.ac.uk \\ Email: c.j.turner@cranfield.ac.uk \\ *Corresponding author
}

Manufacturing and Materials Department, Cranfield University, Bedford, Bedfordshire, MK43 0AL, United Kingdom.

\begin{abstract}
This paper presents the current state of microfluidic design from a practitioner's perspective. The capture of microfluidic design practice was facilitated through a combination of industry survey and expert interviews, allowing the authors to draw out models for microfluidic design. Exploration of the current practice of microfluidic design showed that formal design methodologies were not in use. This research has also found that sub-section interactions have been addressed in an inadequate fashion by current design practices. The work presented in this paper outlines the scope for further research in the development of a formal design methodology for microfluidics.
\end{abstract}

Keywords: Microfluidics, Design Models, Design Engineering, Sub-section Interactions, Design Methodologies.

Biographical Notes: Katarzyna Panikowska is a $\mathrm{PhD}$ student in the Manufacturing and Materials Department at Cranfield University.

Ashutosh Tiwari is Head of the Manufacturing Informatics Centre within the Manufacturing and Materials Department at Cranfield University. Ashutosh's research interests focus on the application of informatics techniques to manufacturing and product design optimisation.

Jeffrey Alcock is a Reader in the Manufacturing and Materials Department at Cranfield University. His research interests include through-life approaches to developing high-performance microsystems and service delivery for microsystems production. 
Christopher Turner is a research fellow and project manager in the Manufacturing and Materials Department at Cranfield University. His research interests include manufacturing informatics, soft computing, and data mining.

\subsection{Introduction}

In the past ten years research into, and the use of, small-sized devices has increased rapidly, highlighting micro-technology as a strong economic driver in the 21 st century. Market research shows not only rapid annual growth in this sector but also trend predictions for its further development. Research and Markets (2013) forecast that the microfluidic device market "will grow swiftly, from \$1.4 Billion in 2013 to \$5.7 Billion by 2018 '. According to Bhushan (2007) 'Microfluidics covers the science of fluid behaviours on the micro-/nano-scales and the design engineering, simulation, and fabrication of fluidic devices for the transport, delivery, and handling of fluids in the order of microliters or smaller volumes".

Although, the initial development of microfluidic devices can be dated to the late 1980s (Tay, 2003) work on design methodologies for this area is still relatively immature. In the past, designers have sought to adapt approaches used in other domains. However, due to differences between domains, this adaptation has fallen short of expectations (Albers, Marz \& Burkardt, 2003). Moreover, a generic design concept in this area has not been developed (Hardt, 2005).

Research has proved that companies with formal NPD (New Product Development) processes are more successful (Martin and Horne, 1992). Therefore, the development of a design methodology for microfluidic devices is a necessity.

Society is shifting towards an 'experience economy' (Tukker, 2004). This transformation could be observed in the 90's in the USA (Wise and Baumgartner, 1999). Researchers identified "that in many manufacturing sectors, revenues from downstream activities represent 10 to 30 times the annual volume of the underlying product sales" (Wise and Baumgartner, 1999). Hence, organisations begin to focus on providing services required for operation and maintenance of products. It has also been found that improved profitability and customer retention is also possible through the pursuit of a service orientation (Voss, 1992). The degree to which a manufacturing organisation concentrates on services depends on the selected approaches. The most 
popular service-oriented approaches are: DFS (Design for Service) (Teresco, 1994; Raplee, 1999; Huang, 1996), PSS (Product Service System) (Manzini \& Vezzoli, 2002, Morrelli, 2002; Mont, 2002; Tukker \& Tischner, 2005, 2006) and SOD (ServiceOriented Design) (Quartel, Dijkman \& van Sinderen, 2004). Though, none of these service-oriented approaches are considered suitable for microfluidics. DFS is restricted to consideration of only one aspect of design (services - mainly maintenance and repair). The PSS approach focuses on organisational changes rather than design flow. SOD, as a formal approach, is focused on IT (Information Technology) and software development, and only its general principles (Sorofan, 2008) may be of benefit to microfluidics.

Orienting the design of microfluidic devices towards services can help bridge the gap expected to be faced by this domain. No single definition of service oriented design has emerged so far though the offering from Ueda (2009) is particularly pertinent 'Service-oriented Design - is a design which supports human centred development by imagining future lives, creating scenarios of services desired by customers and designing products on the basis of this approach'. The authors of this research put forward the following definition in the development of this work 'Service-oriented Design - is a design which supports the development of a 'bundle' of products and services. It incorporates thinking of services and service-based development, leading towards services as an outcome or part of the outcome'.

The increasing complexity of microfluidics (Chatterjee, 2003) has a negative influence on their modelling and micro-architecture in terms of testability and manufacturing cost (Bose, Albonesi \& Marculescu, 2003). This research focuses on sub-section interactions in microfluidics. Since a direct definition of sub-section interactions could not be found, the development of a suitable definition for this research is proposed, by combining the terms 'sub-section' and 'interactions', which resulted in following: Sub-section interactions are understood as relations between modules of the device and their interoperability.

Although research has indicated that micro-scale devices are usually characterised by a high degree of integration of functionalities and components (Tietje \& Ratchev, 2007) and that these interactions among parts and sub-sections play a large role in the micro-design process (Albers, Oerding \& Deigendesch, 2006), an adequate description of this influence and its characteristics has not been identified in the literature. Schabmueller et al. (1999) partially introduced an approach to deal with sub- 
section interactions. Seeking to develop integrated microfluidic systems, they came up with the concept of a microfluidic circuit board as a physical product that allows the connection of different systems together to create one multifunctional device. Shaikh et al. (2005) claimed that existing microfluidic systems often use a monolithic approach, where all of the elements in the device are integrated into a single chip. In their opinion, this leads to compromised functionality in the manufacture of the device. Also, the majority of devices are planar, which creates a need for elaborate channel routing to interconnect components. To overcome these issues, they proposed non planar (3D) modular systems. In addition a number of researchers underline the movement of microfluidics towards modularity (Castellino, 2004, Fitzgerald, 2003, Gilde et al. 2005, Grodzinski et al. 2003, Grodzinski et al. 2004, Miserendino, 2007, Miserendino and Tai, 2008).

Several design models have been identified for microfluidics. However, they are all focused on restricted types of microfluidic devices and have dealt only with issues particular to such designs. For example, Lin and Cheng (2009) presented a design methodology for digital microfluidic biochips focused on pin-count reduction. This methodology is technology driven, presents only the detailed design stage, and is not transferable to other types of device. In later work these authors enhanced their work by cross-contamination awareness; however, the limitations highlighted with their first model still stand (Lin and Cheng, 2010). Similarly, Cortes-Quiroz, Zangeneh and Goto (2009) presented what they named a design methodology for staggered herringbone mixers. Their approach, however, not only is driven by technology but also appears as a 'design optimisation methodology' - and not a 'design methodology'.

Only one model has been identified in the literature as being developed specifically for the microfluidic domain with the potential for application to a variety of devices. Chakrabarty and Su (2005) developed their own 'top-down' methodology for design of biochips. They selected a top-down approach as useful on the system level for the microdomain to speed up the design cycle and reduce human effort. This framework is also discussed in a number of additional works (Chakrabarty \& Zeng, 2005, Su, Chakrabarty \& Fair, 2006). They underlined that this model allows for physical-level simulation and design verification at the component level, by incorporating detailed information about elements of the device. When the physical verification is accomplished, a digital design of the device can be sent for production. 
Chakrabarty and $\mathrm{Su}$ (2005) claimed that in comparison to the full custom design a methodology developed for designing integrated circuits by specifying the layout of each individual transistor and the interconnections between them (Allen, 2005) and bottom-up design methods, the methodology outlined above not only reduced the design cycle time and redesign efforts, but also increased efficiency by dealing with design-fortestability (DFT) and design-for-reliability (DFR) issues. However, they also underlined a number of improvements required for this methodology to be effective. In the main, these consisted of enhancing the synthesis tools for better quality and accuracy of the simulation and of the design result itself, as well as automation of the design process. They also supported the creation and use of design rules particular to microfluidics in order speed up the development.

\subsection{Methodology}

The task of capturing microfluidic design in practice has been approached without the use of preselected methods for the entire process. Selection of each technique used has been a direct result of data analysis from the previous investigation stage. Therefore, the following techniques have been used: literature review, web/brochure analysis, survey and interviews. Based on the results from the literature review and web/brochure analysis further field investigation was been viewed as a necessity, this investigation took the form of a survey.

The survey has been performed using a semi-structured questionnaire for industry and academia to allow for the comparison of responses. A semi-structured approach has been selected to allow designers to express freely their opinions. Key companies and research institutes in the microfluidic area were contacted and asked to complete the survey. With the aim of establishing good contacts, and with respect to the time required from the respondents, only questions viewed as necessary and justified have been incorporated into the survey. The questionnaire was developed by the authors based on literature investigations and results from the initial investigation of companies' offerings from the microfluidic domain. It was evaluated using a piloting session before it was distributed among respondents. An outline of the questionnaire is included in Appendix A. The survey results were analyses according to the methodology outlined in Figure 1. 

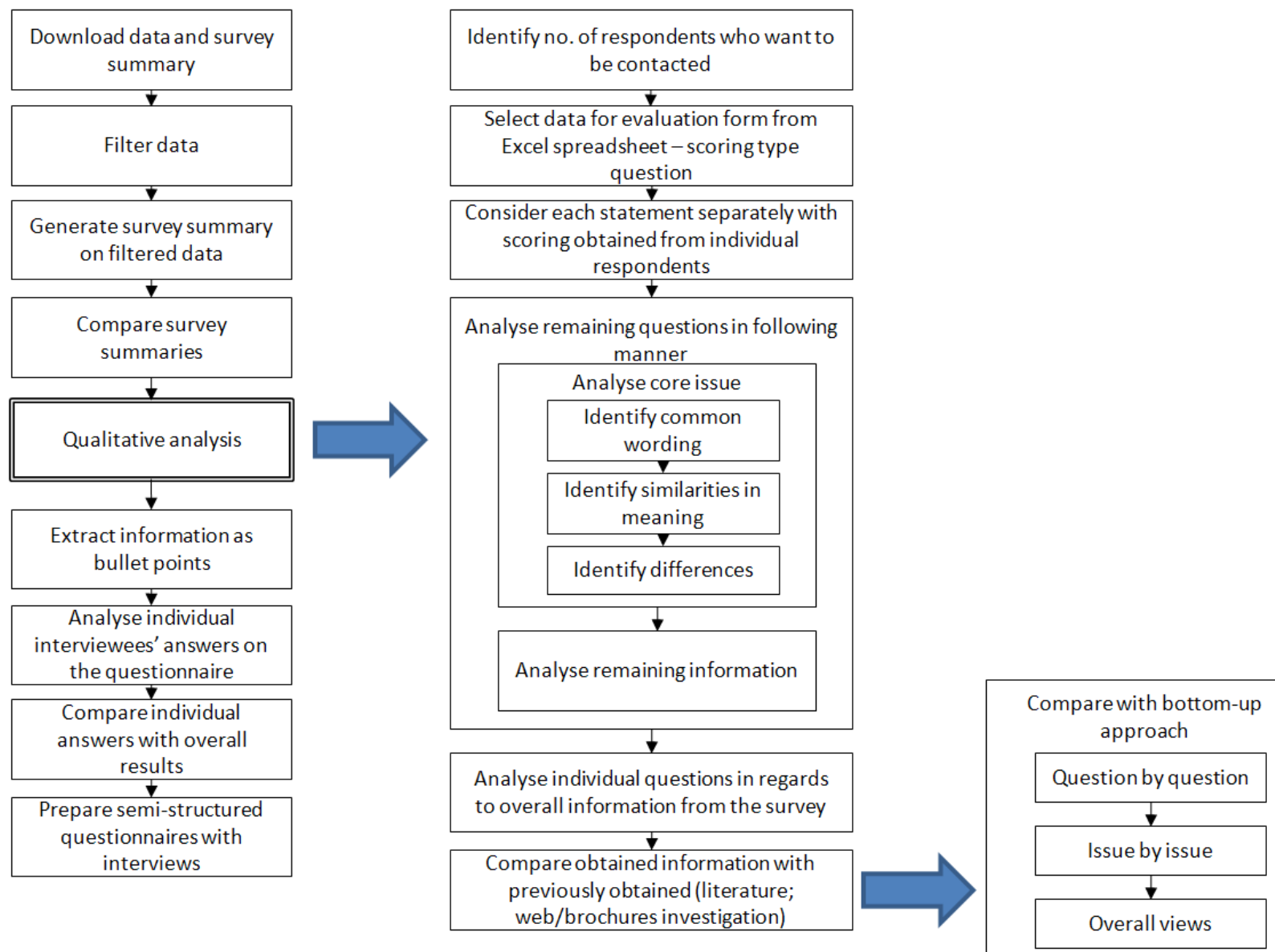

Figure 1: Survey results analysis methodology

After evaluation of the questionnaire, small adjustments were made to make it clearer for respondents. The survey was named "Microfluidics - design, services and modularity" to reflect its three core sections. These sections were: design methodology, service-orientation of products and sub-section interactions. In addition to the survey a set of interviews were also completed. The interviews were designed to follow up on the analysis of the survey stage responses. The interviews were conducted using semistructured questionnaires, personalised for each interviewee. These questionnaires have been developed based on the survey responses given by an interviewee in comparison with responses obtained from other respondents. Comparison between answers from various respondents allowed the authors to establish a list of issues discussed commonly and individually. This list has been used as a base when preparing each questionnaire by comparing it with responses given by a potential interviewee in the survey. A total of 13 respondents completed the questionnaire and 16 respondents were contacted to participate in the interviews. Figure 2 provides more detail on the methodology used to analyse the interview results. 

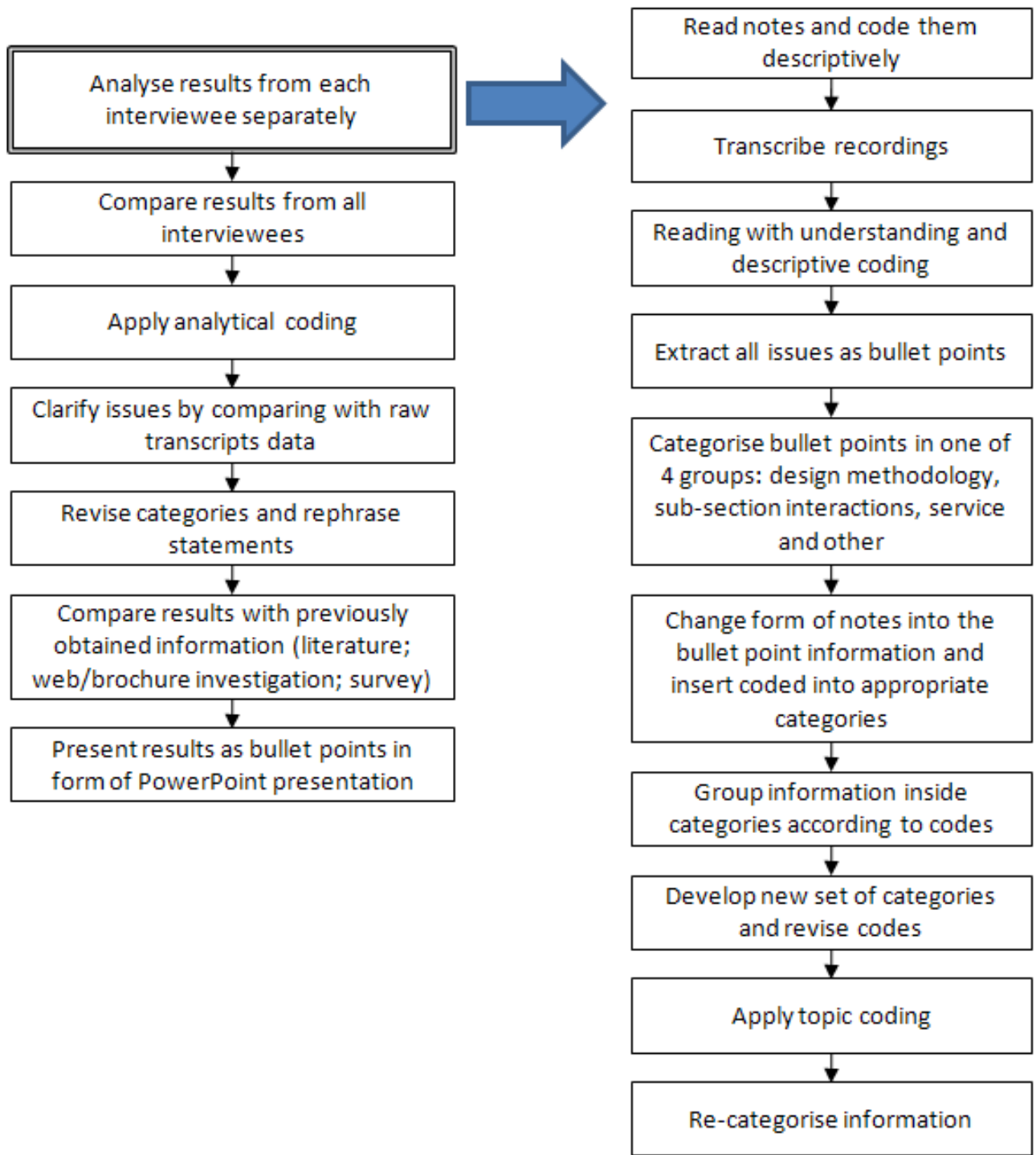

Figure 2: Interview analysis methodology

\subsection{Design Methodologies and Models}

The survey and interviews confirmed that people working on microfluidic device design are not familiar with any formal methodology for design and development of such devices. They do not recognise a general methodology for the domain which could be widely applied. Rather, their work involves using their own in-house developed method on a project by project basis. This investigation confirmed the indications from literature in that the design of microfluidic devices is case dependent (confirmed by $77 \%$ - 10 out of 13 respondents). This case dependence is visible in a number of factors which characterise microfluidic design and in the implicit processes used for it. 
Due to the lack of developed design processes and methodologies for design of microfluidics, a number of models have been extracted from practitioners' responses. These models are presented in this paper. Varying amounts of information can be derived from the models based on their source, survey or interview; therefore, models have been split into these two categories for reader convenience.

\subsection{Models identified via survey}

The survey allowed for extraction of three design processes from respondents' answers. The amount of information in these models is limited. Design processes in the survey were not elaborated by respondents, but only indicated or briefed. Extracted models are presented according to the time order in which they were obtained.

\subsection{Model 1}

The first model (Figure 3) presents the end-to-end design process. It does not include afterlife of the product which, in the case of the majority of microfluidic devices, is omitted due to their disposability. This process includes the method and the source of the input data, as well as the form of the output. It presents the logical transfer between the stages when an input for one phase is an output from the previous one. Moreover, it represents crucial fabrication considerations at an early stage of design. This model shows customer involvement in the decision making process and simulation. Evaluation of the design itself is based here on the simulation results using FEA (Finite Element Analysis) and CFD (Computational Fluid Dynamics) tools. The output of the process is the design sent for fabrication in the organisation of the respondent or, as in many cases as mentioned by literature, in microfluidic foundry. This model seems straight forward; however, it incorporates iteration inside the steps whenever obtained results do not meet the objectives. 


\begin{tabular}{|c|c|c|c|c|c|c|}
\hline Identify needs & $\rightarrow \begin{array}{l}\text { Fabrication } \\
\text { capabilities } \\
\text { investigation }\end{array}$ & $\rightarrow \begin{array}{l}\text { Discussion based } \\
\text { on investigation } \\
\text { results }\end{array}$ & $\rightarrow \begin{array}{l}\text { Assistance in } \\
\text { layout } \\
\text { development }\end{array}$ & $\rightarrow \begin{array}{l}\text { Assistance in } \\
\text { simulation } \\
(\text { FEA/CFD) }\end{array}$ & $\rightarrow$ Testing & $\Rightarrow \begin{array}{l}\text { Sending verified } \\
\text { design to } \\
\text { fabrication }\end{array}$ \\
\hline 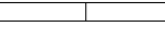 & 1 & 1 & 1 & 1 & 1 & I \\
\hline $\begin{array}{l}\text { Communicate } \\
\text { needs with } \\
\text { clients }\end{array}$ & $\begin{array}{l}\text { Investigate } \\
\text { commercial and/or } \\
\text { academic } \\
\text { fabrication } \\
\text { capabilities to } \\
\text { satisfy client } \\
\text { needs, } \\
\text { Determine process } \\
\text { capable of meeting } \\
\text { physical } \\
\text { requirements }\end{array}$ & $\begin{array}{l}\text { Discussion with } \\
\text { resulting } \\
\text { fabrication } \\
\text { facilities from } \\
\text { step } 2\end{array}$ & $\begin{array}{l}\text { Develop } \\
\text { design kit for } \\
\text { process steps } \\
\text { for } \\
\text { fabrication } \\
\text { technology } \\
\text { (if one isn't } \\
\text { already } \\
\text { present for } \\
\text { supported } \\
\text { design } \\
\text { environment) }\end{array}$ & $\begin{array}{l}\text { Assist in } \\
\text { developing } \\
\text { layout with } \\
\text { clients based } \\
\text { on their needs } \\
\text { and target } \\
\text { technology }\end{array}$ & $\begin{array}{l}\text { Assist in } \\
\text { simulating } \\
\text { design } \\
\text { using FEA } \\
\text { and/or CFD } \\
\text { tools }\end{array}$ & $\begin{array}{l}\text { Send verified } \\
\text { design to } \\
\text { fabrication } \\
\text { facility for } \\
\text { creation to } \\
\text { microfluidic chip } \\
\text { in house/at client } \\
\text { facility }\end{array}$ \\
\hline
\end{tabular}

- Process step

- Information connected to the process step

Figure 3: Microfluidic design models extracted from the survey - Model 1

\subsection{Model 2}

Model 2 (see Figure 4) is the most succinct of those extracted - it appears as just a part of the design process, input and output are not specified here. Iteration is

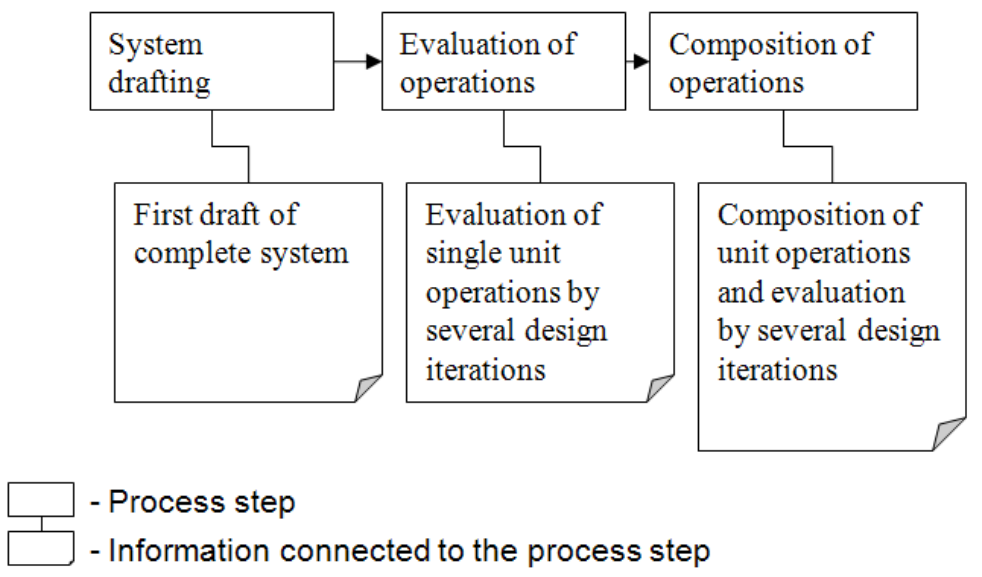

Figure 4: Microfluidic design models extracted from the survey - Model 2

incorporated inside the stages; however, there is no indication of decision making instances. This process does not present any specifics of microfluidics. Not only is it without technological focus, it does not even indicate fabrication consideration needs. This is not a design process, but rather a set of general tasks which are completed in every design and which can fit every product. 


\subsection{Model 3}

The last model extracted from the survey responses (see Figure 5) presents a five stage iterative design. Model 3 does not present the end-to-end design process. Although it indicates input to the process, it does not specify how to obtain it. Phases are named in relation to their outputs or milestones. An exception is the last stage which involves not only the action type description, but also the iterative loop to the beginning of the process. This process indicated that a design is selected based on the CFD simulation results. This model does not explicitly highlight technology considerations in any design stage. Also, it is rather generic and does not present a flow between phases.

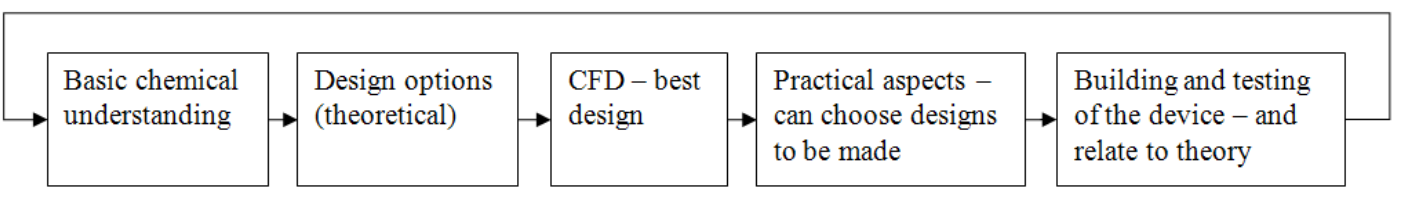

Figure 5: Microfluidic design models extracted from the survey - Model 3

The visualised models present approaches for microfluidic design at various levels of detail and scope. Only one of them is constructed in a fluent manner, allowing understanding of how different phases of work are interconnected to develop a device. The variation of the models underlines the case dependence of microfluidic design. From the obtained answers regarding design of microfluidics, three models were extracted and only a limited amount of information was visualised using them.

\subsection{Models identified via interviews}

To deepen the knowledge on this topic and get a clearer view on it, a set of interviews were also conducted with practitioners. Interview techniques, such as face to face and phone interviews using semi-structured questionnaires, permitted clarification during information acquisition, and by this, increased accuracy and reliability. 


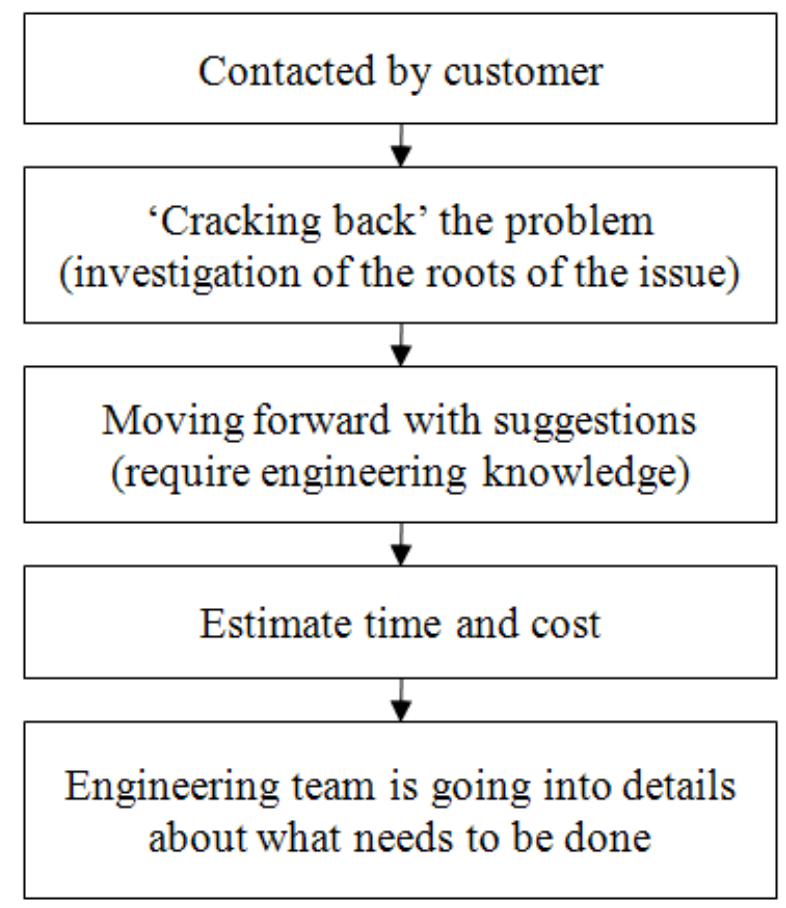

Figure 6: Microfluidic design models extracted from the interviews - Model 1 predesign

Organisations have various methods to approach the design. One of the factors influencing design approach is the sponsorship of the project. The participant of the first interview underlined that in many cases, an additional pre-design stage is necessary before a decision on accepting the project can be undertaken. Moreover, microfluidics should be only developed when they are the answer for a particular issue. This pre-design process is presented in Figure 6. It can be observed that this part of the process also requires knowledge and domain understanding to make decisions regarding the suitability of the approach, and whether the organisation possesses sufficient resources for project realisation. Even before a project is agreed on, the engineering team is involved in the decision making process in a broad context. 


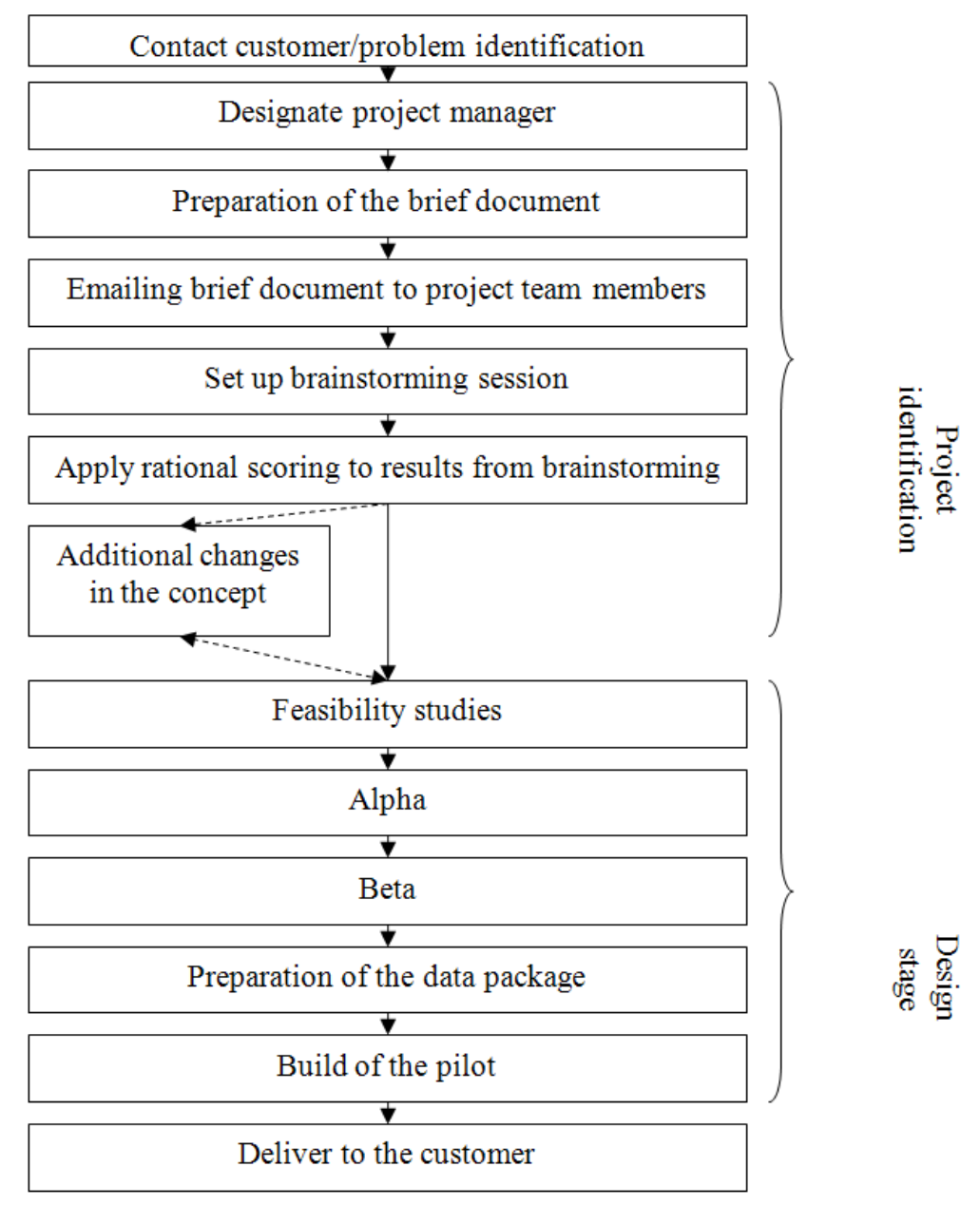

Figure 7: Microfluidic design models extracted from the interviews - Model 1

The design process model is presented in Figure 7. The process is divided into two stages: project identification and design stage. The first part is considered crucial due to the fact that all decisions made at this stage will be executed in the second part, and any iteration should take place here. There are a number of requirements regarding people involved in the design process - their knowledge, competence, background and, most of all, experience. Use of concepts at the early stage of design is automated by usage of a standard method - rational scoring - and creative thinking is encouraged by using brainstorming sessions. However, additional changes in the concepts are allowed, based on their examination using feasibility studies and incorporation of fabrication consideration at the early stage of design (sometimes before the project is undertaken). The presented model is an end-to-end design process. Inputs and outputs are specified in terms of the data ownership and their form. Phases described as 'Alpha' and 'Beta', are detailed design stages in which calculations and modelling are taking place. Both of them are case dependent, which makes 
it difficult to describe them if the organisation is developing various types of microfluidic device. This process does not underline the necessity of simulation as a decision making stage, but instead puts focus on prototyping. Involvement of the customer in this process is not visible throughout, but only at the first and the last step.

\subsection{Model 2 - Interview}

The second model also presents an end-to-end design approach (see Figure 8). It specifies the type and source of input data, as well as output. It underlines that microfluidics is not an answer for every design problem and should not be imposed as one. This process involves the customer in the design, at least at the milestones, which are established by the designer rather than by the client. The outlined model appears straight forward. It does not underline the importance of iteration, which should be minimised due to costs. Also there is a lack of focus on simulation, which is replaced by prototyping as the evaluation method for the device. The interviewee is using model based design as the detailed design stage, which is not described more fully here due to its case dependence.

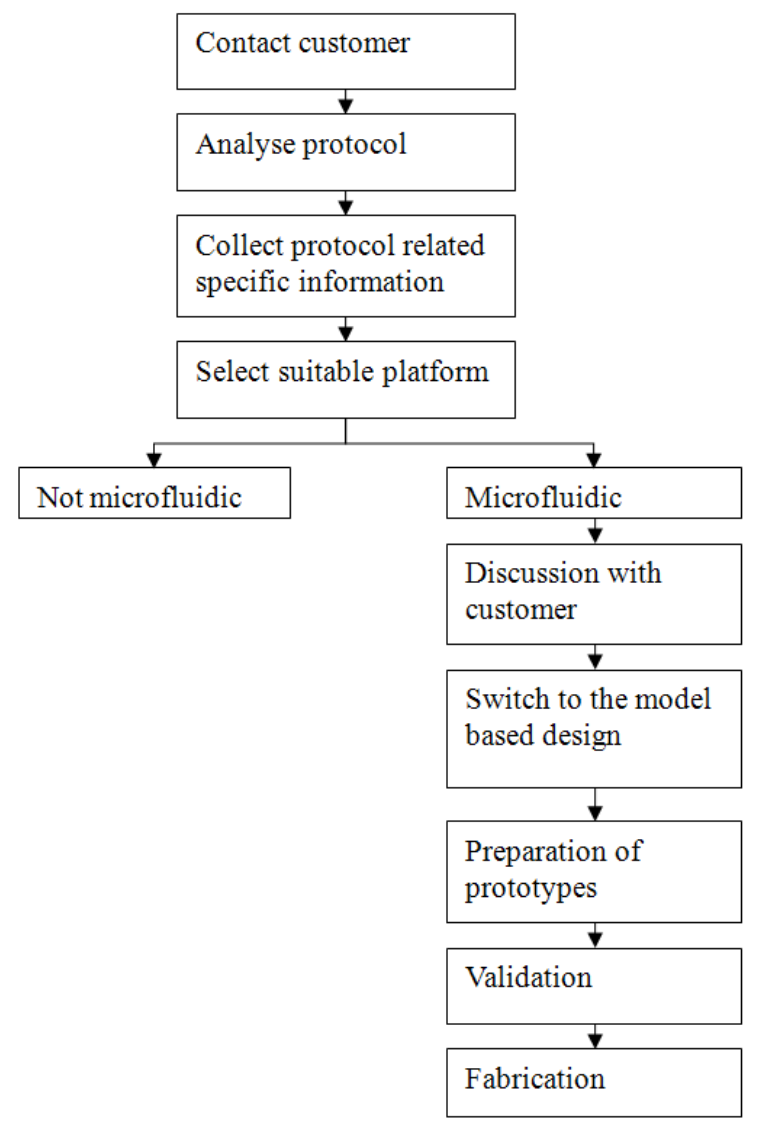

Figure 8: Microfluidic design models extracted from the interviews - Model 2 
This model also incorporates a requirement for knowledge and a deep understanding of the area regarding collection of the protocol related information, selection of the platform for the development of the device and the design itself.

\subsection{Model 3 - Interview}

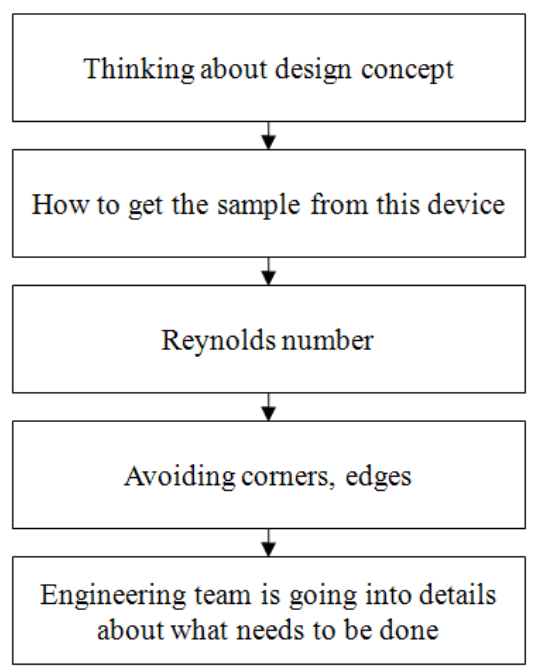

Figure 9: Microfluidic design models extracted from the interviews - Model 3

The third model (see Figure 9) acquired is the shortest obtained from the interviews. It presents a five-stage approach for designing microfluidics. This process is not developed as an action specific set of stages. It consists of steps and data considered by the participant as crucial for microfluidic development. It is not an end-to-end design process. It does not incorporate specified input and there is no clarification on how and from where data are obtained; in addition, the output is not clear. There is no specification of the output form and details of how the product will be validated. This model underlines the importance of technology consideration in microfluidic design. It confirms the fabrication driven approach to design, claimed by literature.

Manufacturing details such as necessity to avoid sharp edges, corners, consider surface quality for possible blockage of the fluid, and change in its behaviour, drive this process. The main difference between the macro- and microfluidics, which is highlighted by the Reynolds number, is explored here to understand basic fluid behaviour that is expected from the device under consideration. This model also underlines the requirement for deep domain understanding and knowledge about fluid behaviour at a micro scale, which has to be supported by experience due to limited understanding of the area. 


\subsection{Model 4 - Interview}

The fourth model presented consists of two variants. Variant A (see Figure 10) presents the design process that is usually employed when the participant is designing to prove a principle. This means that the device is novel, does not exist in the market, and therefore, its performance is unknown. Even in these cases, existing products and functionalities previously developed are investigated to avoid reinventing the wheel. Variant A model presents the end-to-end (no product afterlife phases) design approach. It specifies input and output in terms of its form. Also in this model, simulation is replaced by experiments and prototyping, due to the inability to accurately model behaviour of fluid in micro-scale, especially when principles are under investigation. The presented development process is focused on the functionality of the device under development.

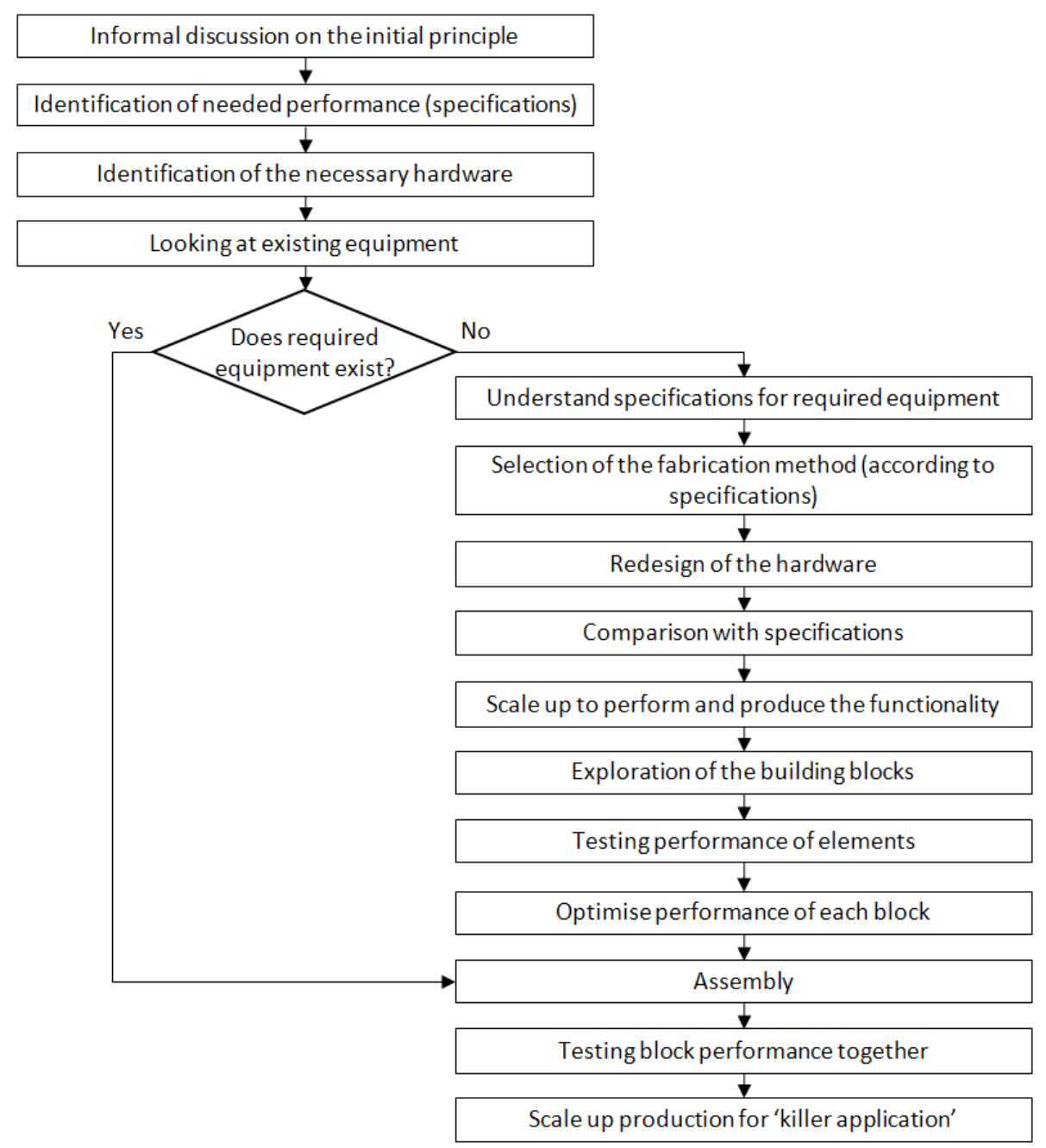

Figure 10: Microfluidic design models extracted from the interviews - Model 4A 
Although technological consideration in terms of the fabrication process does not appear explicitly, every time hardware is mentioned, manufacturing is also brought into view. Therefore, this process is considered as technology driven. It focuses on the testing of elements. It starts as a top-down approach and uses a bottom-up approach for validation to meet specifications.

Variant B (see Figure 11) presents an approach in which the device is developed by request of the customer order. These types of device usually do not require proving principle investigations; therefore, they take less time and the investigation process is less expensive. However, some devices can incorporate elements which are novel, require novel functionality or solutions. The cost of an investigation then increases, and the path followed in variant A takes place. When the device is just a combination of functionalities developed previously, the design process is simplified.

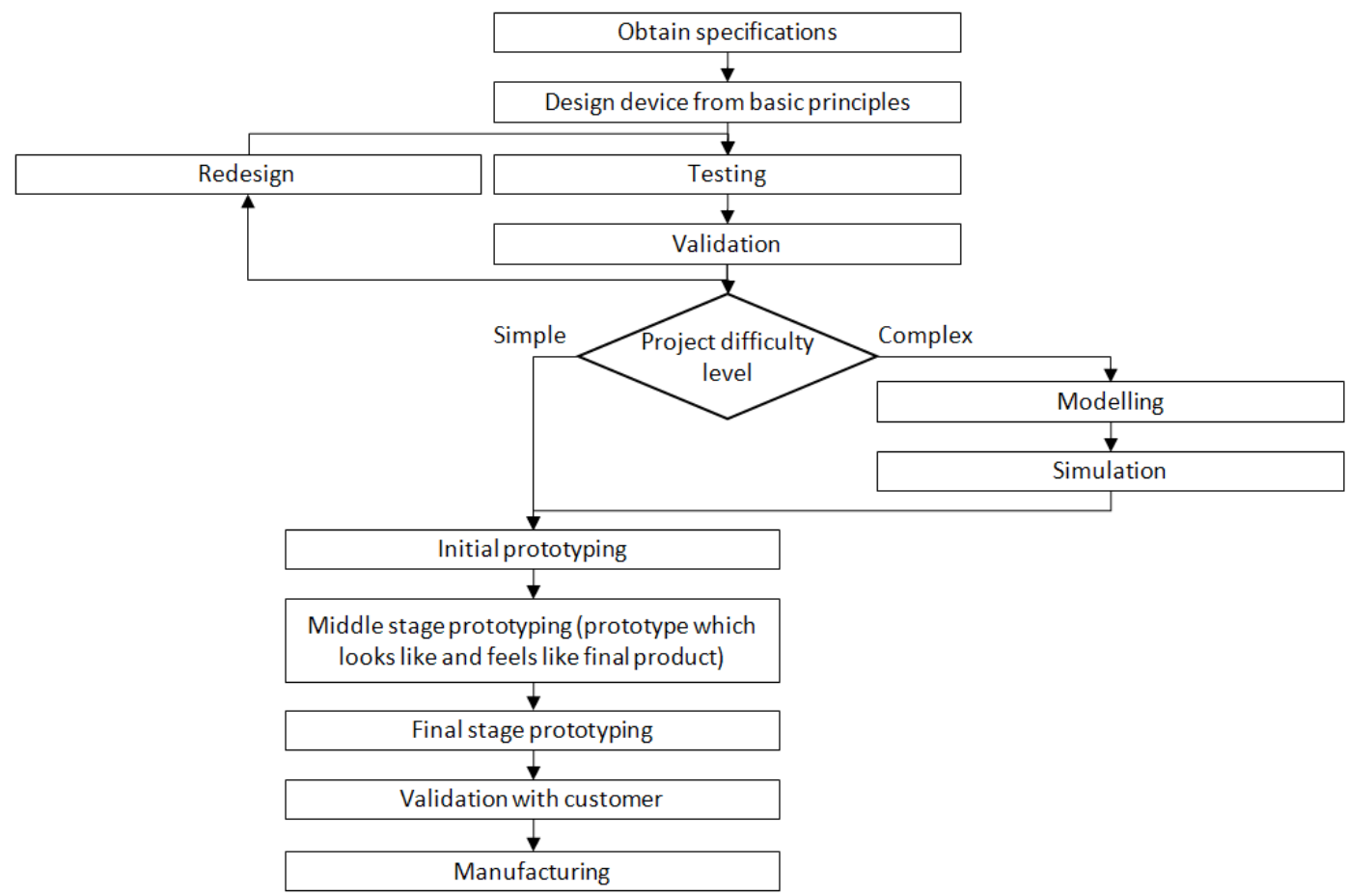

Figure 11: Microfluidic design models extracted from the interviews - Model 4B

The variant B underlines projects for which simulation is considered as justified. Due to cost of simulation and often mismatch with experimental results obtained, this step is omitted when the design is considered simple. More complex devices (combination of various functionalities etc.) are often simulated to minimise cost of variations in prototype developments such as manufacturing cost for complicated 
moulds. Both variants underline the importance of prototyping, especially variant B. Experimentation is considered crucial, as well as knowledge and experience of the designer working on the microfluidic development.

\subsection{Model 5 - Interview}

The last model extracted from the interviews is presented in Figure 12. This process is microfluidics specific. It also presents the end-to end (no product afterlife phases) design process. Methods of obtaining specifications were clarified, as well as an input and an output form. This process is focused on generalisation and automation; these targets are to be achieved through the use of unit operations providing basic functionalities. In this manner, modularity is helping to reduce the development time for future designs.

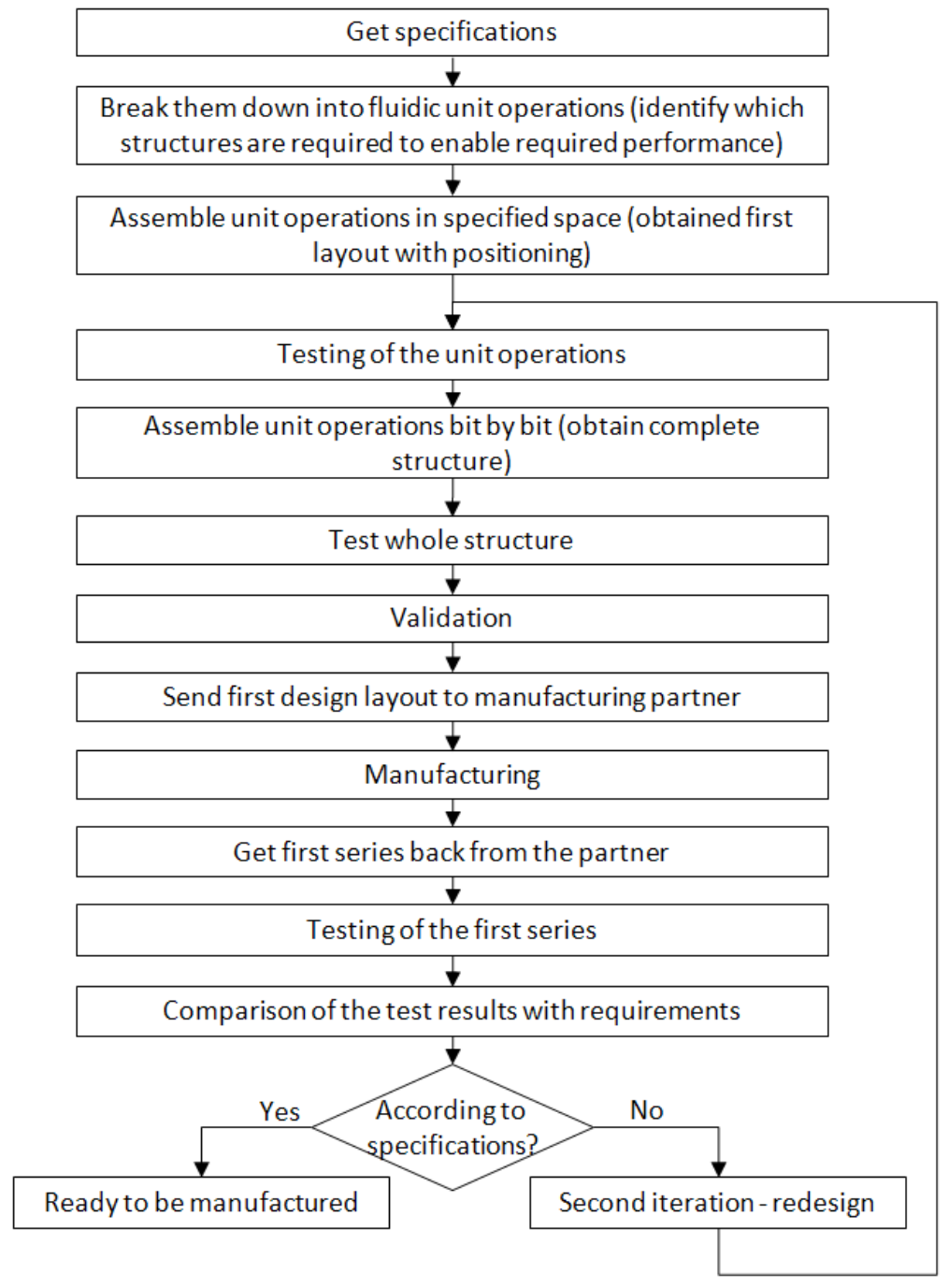

Figure 12: Microfluidic design models extracted from the interviews - Model 5 
As in previous models, the importance of prototyping and testing is underlined. These experiments are used as a validation method for comparison with specifications. In contrast to other processes in Model 5, testing appears after manufacturing due to the use of a foundry at the manufacturing stage, which creates demand for confirmation that devices are of good quality and no faults are incorporated when scaling up production.

Model 5 presents a bottom-up approach to design and development of the product from detail to architecture level. This approach, although considered as beneficial for evaluation in literature, has been underlined as harmful for design of micro-scale devices, due to the fact that the whole device often did not perform according to a standard or did not provide the required functionality.

\subsection{Services and Microfluidic Device Design}

A view on microfluidic organisations practice in terms of services has been obtained via the survey and by follow-up interviews. Results of this investigation contradict literature as the issue of services was hardly mentioned. However, this contradiction has been restricted due to the fact that only limited consideration is paid to services by microfluidic practitioners.

Although the importance of services in microfluidics' future has been underlined by all respondents, and $53 \%$ of them stated that their products are designed as a set of functions with focus on performance, $65 \%$ claimed to consider utilities in the design process and $70 \%$ to incorporate service thinking in the design; a confirmation of these claims could not be obtained. This lack of service presence can be observed in the microfluidic design models identified in the previous section.

From the survey $59 \%$ of respondents' organisations offer utilities for microfluidic products, which confirm the initial investigation's finding regarding higher maturity of the area in terms of services. But types of service consideration in terms of offerings for microfluidics were restricted to the support of support more complicated equipment with software, maintenance and repair for platforms (not disposables) and design services for microfluidics.

Due to the fact that the majority of microfluidic devices are designed as disposable, and a high percentage of their application is in the medical domain where 
contamination is a sensitive and important issue, consideration of the product life after sale is minimal. Regulations discourage the majority of organisations from taking any responsibility for collecting and disposing of used devices as a service. Therefore, users are solely responsible for this, and the service opportunity is not explored.

The design services offered are identified by providers as very flexible and customisable. They are developed based on a business plan in the majority of organisations. Not all organisations view flexibility in the same way. In a few cases, flexibility and customisability means selection from a catalogue, i.e. choice from provided options such as dimensions, production, and flow.

Issues connected to both monolithic and modular approaches, and identified as critical for microfluidics, are sub-section interactions and, more precisely, interfaces. Although people underline the importance of this issue, they fail to address it properly. Although 70\% (7 out of 10) of respondents work in organisations which influence subsection interactions, only $22 \%$ ( 2 out of 9) confirm familiarity with methods to deal with it. Organisations lack established methods to assess interfaces. Some of them are trying to standardise interfaces of products and operation units inside them, to provide a base for fast reconfiguration and add-ons. However, this situation is rare. More often, organisations limit themselves to minimise the number of interfaces leading to integration. One of the methods to deal with this issue is usage of connectors. These elements evolved from a simple need for leakage proof fluid channelling and as a result forced organisations to develop common interfaces which allow for interchangeability.

Organisations do not provide any other service type offerings. Leasing of microfluidics, in their opinion, is too risky (contamination), and scientific contracts (outside research) are considered as beneficial only by a small number of respondents. $70 \%$ of respondents claimed to incorporate service thinking in the design, but the majority of them tended not to consider potential add-ons for their products, which may create service opportunities. According to a majority of respondents, any work beyond providing basic functionality to the device is not considered. Only a limited number of organisations incorporate add-on considerations as actions in their design process, and when doing so, they focus on interfaces: within the product and with the environment, on both micro- and macro- scale. Given the described characteristics, the presence of services and service-thinking has been recognised in the area - although, the full potential is not exploited. 


\subsection{Discussion}

The use of both survey and interview techniques has allowed the authors to obtain a broader perspective of the issues concerning design practices for microfluidic devices. In addition views on the incorporation of service offerings with such devices have been investigated along with the effect of sub section interactions on microfluidic device designs. Exploration of the current practice of microfluidic design showed a lack of use of formal design methodologies. A general design process to be applied across the domain has not been identified; although the requirements for standardisation and automation demanding it were clearly stated. Design models, when extracted, vary in details. However, all models identified were driven by technology and, more precisely, fabrication.

A number of factors influencing design - such as limited knowledge about particular aspects of microfluidics (e.g. behaviour of certain liquids) multidisciplinary team, hands-on experience - have been identified as necessary for inclusion but missing in some of the existing approaches. Results of an investigation of service practice in the microfluidic domain contradicted the limited volume of literature regarding this topic. Service offerings for microfluidics have been identified as existing and going beyond 'manufacturing for others' and 'designing for others'. Although the presence of a limited number of services has been noted and no pattern across them discovered, their existence provides an indication that practitioners are making steps outside of purely technological development, and that the first step towards an 'experience economy' in this area has been taken. Nevertheless, no service-orientation has been identified in the design processes in the domain. The importance of services and service connected considerations has been acknowledged by practitioners, but this could not be confirmed in the description of their work. Moreover, a negative attitude towards offerings outside the traditional scope has been recognised in many cases.

Similarly, the topic of sub-section interactions has been identified as crucial by practitioners. However, the ways in which they try to tackle this concept have been inadequate given the importance of the issue. A limited number of informal methods have been identified, but none of the practitioners were able to indicate any formal method used by their organisation to deal with aspects of sub-section interactions. The move towards standardisation has been identified as a common factor in the domain; however, organisations are attempting to standardise using a variety of methods. One of 
the important aspects of sub-section interactions, according to practitioners, is the interface - between components/modules and with the environment. Moreover, this issue can provide a method to address sub-section interactions' impact by moving towards standardisation.

\subsection{Conclusion}

The microfluidic domain has been identified as more mature than the limited volume of literature available on it would suggest. An overlap of service-orientation, sub-section interactions and design methodologies has not been identified explicitly and/or implicitly. However, the importance of all three subjects has been underlined by practitioners. Due to the high customisation potential of microfluidics and promising forecasts of this area's financial prospects the indications are that the movement towards an 'experience economy' has already started in this domain. Although subsection interactions have been identified as crucial for microfluidics, formal methods to address this area were not identified in the domain.

\subsection{Recommendations}

Development of standard connectors and interfaces minimise the types of interactions which can occur and, hence, simplify the design. To this end there should be a focus on the interfaces and development of standard elements. The development of a 'pick and play' type of database detailing available microfluidic modules may also help address the issues posed by sub-section interactions. mService-orientation can be addressed in microfluidics by the incorporation of service considerations into the design process. However, this incorporation needs to be done in a flexible manner, taking into account the reluctance of potential users to go 'out of their comfort zone' (new type of offerings) and various levels of organisations' maturity in terms of services and the service foundation possessed by them (service type offerings, delivery systems in place, service planning processes, etc.). In future research the authors plan to explore the microfluidic domain from the customers' point of view. This service based approach will include the categorisation of services demanded and types of offerings most likely to attract customers. In addition the area could benefit from a set of rules for the selection of the most suitable manufacturing method for particular types of microfluidics. 


\section{Appendix A:}

\section{Outline of Survey Questions}

This appendix provides an outline of the survey sections and a sample of the questions used.

\section{Design Methodology section}

This section checks the familiarity of the respondent with any design methodology for microfluidic devices. This methodology can be formal in which case the name of it will be sufficient for identification or can be created 'in house' or as a result of modification of existing literature approaches in which case the description of the method will be necessary.

This section includes questions such as:

- Did you follow any particular methodology when designing microfluidic device(s)?

This answer provides information on whether the respondent is familiar with any design methodology for microfluidic devices. This methodology can be formal in which case the name of it will be sufficient for identification or it can be created 'in house' or as a result of modification of existing literature approaches in which case a description of the method will be required.

- Do you develop more than one type of microfluidic device?

Selection of this question is based on the possibility of more than one type of microfluidic device being offered by the organisation. To avoid any misunderstanding the indication of the most well established design is requested.

- Were the customers involved in the design process?

There is no indication about customer role in the design of microfluidic devices. This question provides answers on the involvement of the customer and requests 
additional information such as: which stages, what type of involvement and what input was provided by the customer.

- Did you use any methods to capture customer needs and expectations from the product?

This answer provides an insight into the methods used to capture customer needs and expectations. It shows if the design practice is more oriented towards customer or technology, as indicated by literature.

- Please describe the design process for this device step by step?

Each design process is unique in some aspects. Regarding various factors which designers can and cannot influence a description of the followed design path for a particular microfluidic device is requested.

\section{Service-orientation of products section}

This section asks about the service orientation inherent in the respondent's microfluidic products.

This section includes questions such as:

- Does your company offer any services with microfluidic products?

Regarding the lack of information about services in literature this question is the first to be asked in this section.

- Did you incorporate services (service thinking) into the design process?

Service thinking in the design differs from thinking about services as utilities.

- In your opinion how important are services in today's microfluidic market and how important will they be in the future?

This question captures companies' views on services in the microfluidic domain in terms of utility and movement toward functionality offerings. The answers 
show if the area is more mature in the industry than in academia or services are still not considered, even as a future direction.

\section{Sub-sections interactions section}

This section identifies if the respondent has first-hand experience of dealing with modular designs. If a respondent is able to answer the questions in this section a possible follow-up interview could be used to gather further details.

This section includes questions such as:

- Does your company offer/design modular or monolithic microfluidic devices? This question identifies the respondent has the first-hand experience of dealing with modular designs.

- How important in your opinion (and/or in vision of the company) are the interactions between sub-sections in the modular device (for microfluidic and for any other device)?

This question identifies views of the respondent on modularity and sub-section interactions.

- Did your company influence sub-section interactions in any way?

The answer to this question provides information about industrial practice in companies dealing with sub-section interactions.

\section{References}

Albers A, Marz J, \& Burkardt N (2003) Design Methodology in Micro-Technology”, in: International Conference on Engineering Design ICED'03, 19-21 August, Stockholm, Sweden.

Albers A, Oerding, J, \& Deigendesch T (2006) Product Development Regarding Micro Specific Tasks - Challenges in Designing for Production and Assembly, in: 2006 CIRP (College International pour la Recherche en Productique) International Design Seminar, 16-19 July, Kananaskis, Alberta, Canada. 
Allen, J. J. (2005). Micro electro mechanical system design. CRC Press, Boca Raton, USA.

Bhushan B (2007) Springer Handbook of Nano-technology (2nd ed.), Springer, Columbus, OH, USA.

Bose P, Albonesi D H, \& Marculescu D (2003) Guest Editors' Introduction: Power and Complexity Aware Design. IEEE Micro 23(5):8-11.

Castellino V (2004) Microfluidics Tools for Systems Biology. University of Toronto, available at: http://www.ecf.utoronto.ca/ sdavies/sysbioldir/sysbio04/Microfluidic\%20Tools \%20for\%20Systems\%20Biology.doc (accessed 14th October 2014)

Chakrabarty K, \& Zeng J (2005) Design Automation for Microfluidics-Based Biochips, ACM J Emerg Technol 1(3):186-223.

Chatterjee A (2003) Generalized numerical formulations for multi-physics microfluidics-type applications, J Micromech Microeng, 13:758-767.

Cortes-Quiroz C A, Zangeneh M, \& Goto A. (2009) On multi-objective optimization of geometry of straggered herringbone micromixer, Microfluid Nanofluid, 7(1):2943.

Fitzgerald D A (2003) Macro Opportunities in Microfluidics: Market fluidity reigns as a crowded sector matures. The Scientist 17(11):39-39.

Gilde M J, van den Vlekkert H, Leeuwis, H, \& Prak, A (2005) Modular Design Approach for MicroFluidic Systems. NSTI-Nanotech Nanotechnology Conference and Trade Show 1:684-687.

Grodzinski P, Yang J, Liu R, \& Ward, M D (2003) A modular microfluidic system for cell pre-concentration and genetic sample preparation. Biomed Microdevices 5(4):303-310.

Grodzinski P, Liu R, Yang J, \& Ward M D (2004) Microfluidic system integration in sample preparation chip-sets - a summary, in: 26th Annual International Conference of the IEEE EMBS. September 1-5, San Francisco, CA, USA, 26152618.

Hardt S (2005) Design paradigm and methodologies for microfluidic, NSTI-Nanotech 2005, Nanotechnology Conference \& Trade Show, 1:567-570.

Huang G Q (1996) Design for X: concurrent engineering imperatives, Chapman \& Hall, London, UK. 
Lin C C-Y. \& Cheng Y-W (2009) ILP-Based Pin-Count Aware Design Methodology for Microfluidic Biochips, IEEE T Comput Aid D, 29(9):1315-1327.

Lin, C.C.-Y. and Cheng, Y.-W. (2010) Cross-Contamination Aware Design Methodology for Pin-Constrained Digital Microfluidic Biochips, in: Design Automation Conference DAC'10, 13-18 June, Anaheim, CA, USA, 641-646.

Manzini E, and Vezzoli C (2002) A strategic design approach to develop sustainable product service systems: examples taken from the 'environmentally friendly innovation' Italian prize, J Clean Prod, 11:851-857.

Martin C R, \& Horne D A (1992) Restructuring towards a Service-Orientation The Strategic Challenges, Int J Serv Ind Manag, 3(1):25-38.

Miserendino S (2007) A Modular Microfluidic Approach to Nano High-Performance Liquid Chromatography with Electrochemical Detection (Doctoral dissertation), California Institute of Technology, Pasadena, CA, USA.

Miserendino S, \& Tai, Y.-C. (2008) Modular Microfluidic Interconnects using Photodefinable Silicone Microgaskets and MEMS O-rings, Sensors and Actuators, Part A, 143:7-13.

Mont O (2002) Clarifying the Concept of Product-Service System, J Clean Prod, 10(3):237-245.

Morrelli N (2002) Designing product/service systems: A methodological exploration. Des Issues 18(3):3-17.

Quartel D, Dijkman R, \& van Sinderen M (2004) Methodological Support for Serviceoriented Design with ISDL, in: 2nd International Conference on Service Oriented Computing ICSOC’04, 15-18 November, New York, NY, USA. Raplee J (1999) DFMA to RP, ASAP, Mechanical Engineering, 121(9):72-74. Research and Markets (2013) Microfluidic Applications in the Pharmaceutical, Life Sciences, In-Vitro Diagnostic and Medical Device Markets Report 2013, http://www.researchandmarkets.com/reports/2633004/microfluidic_applications _in_the_pharmaceutical (accessed 14th October 2014).

Schabmueller C G J, Koch M, Evans, A G R \& Brunnschweiler A, (1999) Design and fabrication of a microfluidic circuitboard, Journal of Micromechanical Microengineering, 9:176-179.

Shaikh K A, Ryu K S, Goluch E D, Nam J, Liu J, Thaxton C S, Chiesl T N, Barron A E, Lu Y, Mirkin C A, \& Liu C (2005) A modular microfluidic architecture for 
integrated biochemical analysis, Proceedings of The National Academy of Sciences of the USA. 102(28):9745-9750.

Sorofan J, (2008) The service orientation of... everything, IBM, available at: http://searchsoa.techtarget.com/tip/0,289483,sid26_gci1303762,00.html (accessed 14th October 2014).

Su F, Chakrabarty K, \& Fair R B (2006) Microfluidics-Based Biochips: Technology Issues, Implementation Platforms, and Design-Automation Challenges, IEEE Transactions on Computer-Aided Design of Integrated Circuits and Systems, 25(2):211-223.

Tay F E H (2003) Microfluidics and BioMEMS Applications, Kluwer Academic Publishers, Netherlands.

Teresco J (1994) Service now is a design element, Industry Week, 243(3):51-52.

Tietje C, \& Ratchev, S (2007) Design for Microassembly - A Methodology for Product Design and Process Selection, in: IEEE International Symposium on Assembly and Manufacturing, 22-25 July, Ann Arbor, Michigan, USA, 178-183.

Tukker A (2004), Eight types of Product-Service System: Eight Ways to Sustainability? Experiences from Suspronet, Business Strategy and the Environment. 13:246260.

Tukker A, \& Tischner U (2005) New Business for Old Europe. Product-Service Development, Competitiveness and Sustainability, Greenleaf Publishing, Sheffield, UK.

Tukker A. \& Tischner U (2006) Product-services as a research field: past, present and future. Reflections from decade of research, J Clean Prod, 14:1552-1556.

Ueda Y (2009) Proposal for Service-Oriented Design Processes, FUJITSU Scientific and Technical Journal, 45(2):171-178.

Voss C (1992) Applying Service Concepts in Manufacturing, International Journal of Operation \& Production Management, 12(4):93-99.

Wise R, and Baumgartner P (1999), Go Downstream: The New Profit Imperative in Manufacturing, Harvard Business Review, September-October, 133-141. 
2016-12-01

\title{
Design practices used in the
}

development of microfluidic devices: a

services-based view

\author{
Tiwari, Ashutosh
}

Inderscience

Panikowska K, Tiwari A, Alcock J, Turner C. (2016) Design practices used in the development of microfluidic devices: a services-based view. International Journal of Manufacturing

Technology and Management, Volume 30, Issue 6, 2016, pp. 422-442

https://www.doi.org/10.1504/IJMTM.2016.081594

Downloaded from Cranfield Library Services E-Repository 